\title{
How to build a low-cost underwater camera housing for aquatic research
}

\author{
Jonathan A. Bergshoeff $^{\mathrm{ab} \dagger}$, Nicola Zargarpour ${ }^{\mathrm{ab} \dagger}$, George Legge ${ }^{\mathrm{a}}$, and Brett Favaro ${ }^{\mathrm{ab} *}$ \\ ${ }^{a}$ Centre for Sustainable Aquatic Resources, Fisheries and Marine Institute of Memorial University of

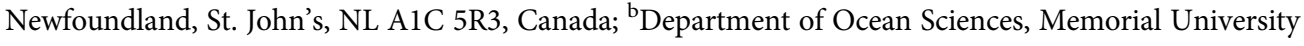 \\ of Newfoundland, Logy Bay, NL A1K 3E6, Canada \\ *Brett.Favaro@mi.mun.ca \\ ${ }^{\dagger}$ These authors contributed equally to this work.
}

\begin{abstract}
Remote cameras are an increasingly important tool in field-based biological research. Terrestrial researchers can purchase inexpensive off-the-shelf cameras, but aquatic researchers face challenges in adopting similar systems for underwater science. Although technology allows researchers to deploy cameras in any aquatic environment, high procurement costs are often a barrier, particularly for studies that require the collection of lengthy videos. In this note, we provide a detailed guide explaining how to assemble an underwater camera system for less than \$425 USD. We focus especially on the construction of the underwater housing, which is typically the most expensive component of an underwater camera system. As described, this system can record $13 \mathrm{~h}$ full highdefinition videos in depths up to $100 \mathrm{~m}$. It can be constructed and assembled with limited technical background using tools available in most workshops. The guide includes a general overview of the system, a full list of components, detailed instructions on constructing the camera housing, and suggestions on how to mount and use the camera in fieldwork. Our goal for this note is to promote the wider use of remote underwater cameras in aquatic research by making them accessible to those with limited financial means.
\end{abstract}

Key words: action camera, remote camera, digital video, behaviour, benthic ecology, science communication

Citation: Bergshoeff JA, Zargarpour N,
Legge G, and Favaro B. 20 I 7. How to build a
low-cost underwater camera housing for
aquatic research. FACETS 2: I 50-159.
doi: I 0.1 I 39/facets-20 I 6-0048
Editor: Sophia Johannessen

Received: September 12, 2016

Accepted: December 13, 2016

Published: February 16, 2017

Copyright: (c) 2017 Bergshoeff et al. This work is licensed under a Creative Commons Attribution 4.0 International License (CC BY 4.0), which permits unrestricted use, distribution, and reproduction in any medium, provided the original author(s) and source are credited.

Published by: Canadian Science Publishing

\section{Introduction}

Aquatic science relies on technologies that provide information about the underwater environment. Underwater cameras are a widely used tool to perform direct observations on the behaviour of organisms in their native habitat and can greatly supplement the data derived from other means. As an example, cameras can be used to study the behaviours of organisms that interact with static (e.g., Renchen et al. 2012; Bacheler et al. 2013; Favaro et al. 2014) and mobile fishing gear (e.g., Nguyen et al. 2014; Underwood et al. 2015) in situ.

The merits of applying camera systems in biological studies have been amply demonstrated in the terrestrial realm, where a mature body of evidence has described their application to studying ecosystems (O'Connell et al. 2011). Many of these systems are inexpensive and readily available as off-the-shelf products, which has assisted in the proliferation of this study technique. In contrast, underwater camera systems can be substantially more expensive, due primarily to the challenges associated with operation in an aquatic environment. 
The utility of underwater cameras for aquatic science depends in part on the specifications and capabilities of the camera gear (Favaro et al. 2012; Underwood et al. 2012; Struthers et al. 2015). For cameras that are self-contained (i.e., do not need to be connected to a boat or other fixed power source at the surface), there are essentially two categories: expensive systems that are highly capable; and inexpensive systems that are limited in battery life, safe operating depth, storage capacity, and low-light sensitivity (e.g., Struthers et al. 2015). For researchers that need to record video for longer periods of time (e.g., studying deployed fishing gear), systems specific to the project often have to be designed and built (e.g., Jury et al. 2001; Bacheler et al. 2013). Trial-and-error associated with the design and construction process can add to the cost of underwater projects and prevent them from being completed in a timely manner. This can result in researchers avoiding the use of underwater cameras, or selecting off-the-shelf cameras that can only record for short durations due to limitations in battery life.

In this note, we describe a camera system that we constructed from components available at general hardware and consumer electronics stores. There are four components to this system: the camera itself, the external battery pack, the housing, and the mounting frame connected to the fishing gear (or other structure) under examination. We devote most of this note to describing the construction of the underwater camera housing, which is often the most expensive component to procure when assembling a camera system for aquatic research. The underwater housing described in this note was adapted from a design shared on a hobby website (Anonymous 2006). The total cost of components for one housing was \$145 USD (Supplementary Material 1).

With proper care taken in construction, the housing is capable of being safely used at depths up to $100 \mathrm{~m}$. It is large enough to contain a small camera such as a Sony Action Cam with an additional battery pack, and the configuration we describe in this note is capable of recording full high-definition videos at 1080p resolution for $13 \mathrm{~h}$ (Sony Corporation 2014). This note provides sufficient detail for someone with limited technical experience to procure the materials and construct the underwater camera housing. Our hope is that this note empowers researchers to construct inexpensive housings that facilitate the collection of long-duration video recordings in aquatic environments.

\section{Materials and methods}

\section{Camera components and necessary tools}

We selected a Sony HDR-AS20 Action Cam and attached an Anker Astro E4 13000 mAh battery pack (any battery pack with at least a $10000 \mathrm{mAh}$ capacity and a USB connection should suffice) to increase battery life and recording duration. Using a 128 GB Micro SDXC memory card, we were able to record continuously for $13 \mathrm{~h}$ at $1080 \mathrm{p}$ resolution.

The tools required for this project comprise: pencil, marker, tape measure, ruler, calipers, miter saw equipped with a plastic-cutting blade, band saw, lathe, scissors, fine sandpaper, masking tape, four

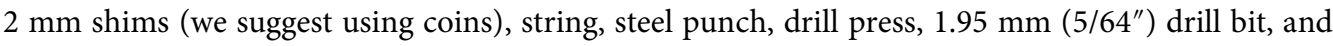
a No. 1 green Robertson screwdriver. Figure 1 shows a completed housing, and Fig. 2 shows the raw materials and hardware needed for its construction. Finally, Supplementary Material 2 demonstrates how to execute each step of the construction process.

\section{Construction of the underwater housing}

To construct the underwater housing, detailed instructions are provided in Supplementary Materiall 3 with accompanying photos and text describing how to complete each step. We recommend using these instructions while reviewing the accompanying video (Supplementary Material 2) to aid in the construction process. These instructions guide the researcher through preparation of all the 


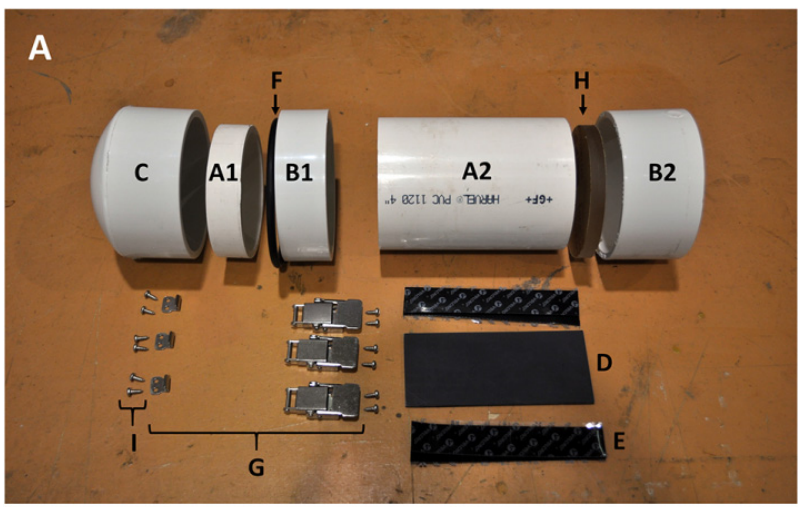

Fig. 1. Disassembled camera housing, showing (A) all components prepared for assembly, with part labels corresponding with those in Fig. 2, and (B) completed housing.

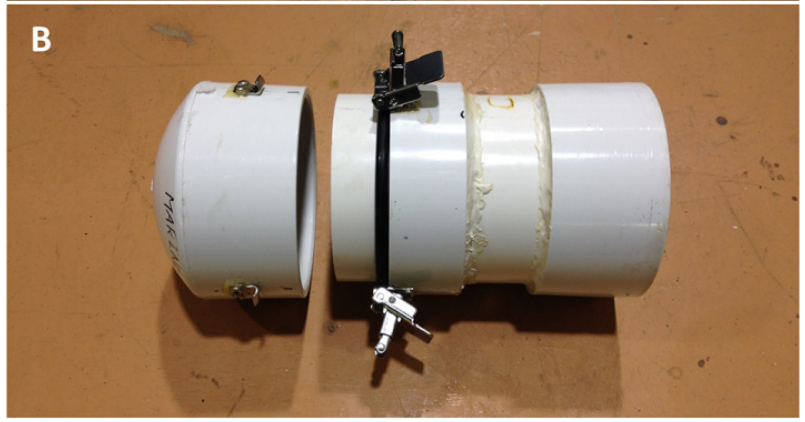

necessary components and assembly of the completed housing (Fig. 1). We also include a description of each component and its price at the time of writing (Supplementary Material 1).

The housing itself consists of two main parts: the body of the housing and the end cap that latches firmly onto the body to form a watertight seal. The body contains the camera and external battery, and features a clear, acrylic viewport on the front end. The housing is constructed using $10.16 \mathrm{~cm}$ diameter ( $\left.4^{\prime \prime}\right)$ schedule 40 (0.6 cm wall thickness) PVC piping components. We used schedule 40 PVC components as they are inexpensive, widely available, and durable. The components required to construct the housing are widely available at most hardware stores, and the housing can be constructed and assembled with limited technical background using tools available in most workshops.

Construction of the housing does not take a large amount of time and is mostly limited by the time required for the epoxies and adhesives to fully cure. For example, the final step in construction of the housing requires the use of $3 \mathrm{M}^{\mathrm{TM}} 5200$ marine adhesive sealant, which specifies a cure time of 5-7 d. We estimate that preparation of the component pieces and actual assembly time should take approximately $4-5 \mathrm{~h}$.

\section{Use in the field, care, and maintenance}

The underwater housing can be affixed to fishing gear or other structures. For our research project, we built wooden frames to mount the camera systems to crab pots, similar to the designs of Jury et al. (2001) and Favaro et al. (2012) (Fig. 3). We held the underwater housing firmly in place using a large 114-165 mm diameter gear clamp that allowed for easy mounting and removal of the camera housing. Depending on the application, researchers must consider whether to add external lighting. If external lighting is used, we recommend using lights capable of consistent illumination for the duration of video recording (to avoid illumination problems such as those experienced by Favaro et al. 2012). We also recommend red lights, as they are less visible to many marine organisms than 


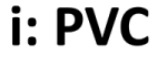

\section{A1, A2}

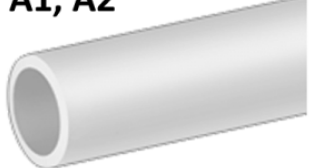

$10.16 \mathrm{~cm}(4 ")$ schedule 40 PVC pipe

B1, B2

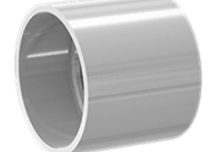

$10.16 \mathrm{~cm}(4 ")$ schedule 40 PVC coupling

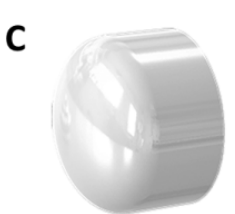

$10.16 \mathrm{~cm}$ (4") schedule 40 PVC unthreaded cap

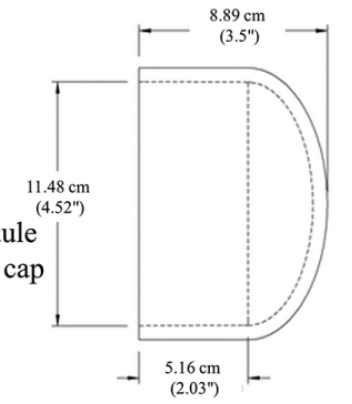

\section{ii: Camera Mount}

D

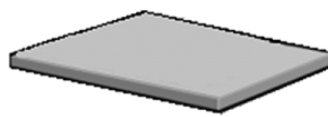

$0.32 \mathrm{~cm}\left(1 / 8^{\prime \prime}\right)$

PVC sheet

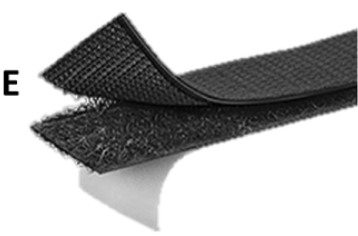

$3.54 \mathrm{~cm}(1 ")$

Industrialstrength hook \& loop iii: Hardware

$\mathbf{F}$

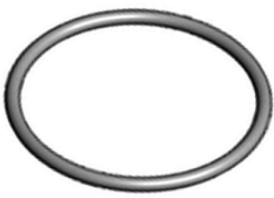

$\mathbf{G}$

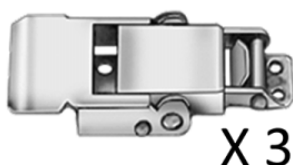

H

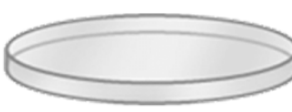

Optically clear acrylic circle, $1.27 \mathrm{~cm}(1 / 2 ")$

thickness, $12.7 \mathrm{~cm} \mathrm{(5")}$ diameter

I

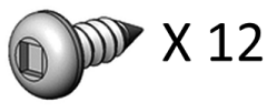

Stainless steel screw,

No. 6, $0.95 \mathrm{~cm}\left(3 / 8^{\prime \prime}\right)$

\section{iv: Adhesives}

J Clear PVC cement

K Clear PVC primer

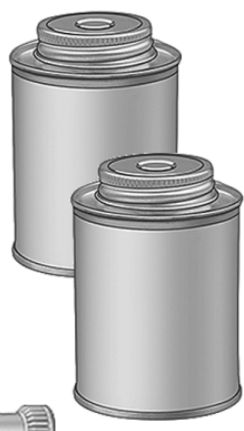

L

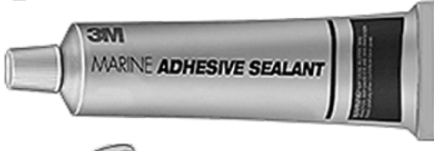

$3 \mathrm{M}^{\mathrm{TM}} 5200$

marine sealant

M

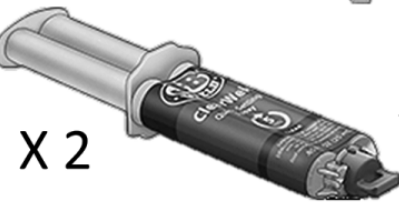

Adhesive epoxy*

*Self-mixing epoxy is preferable (e.g. Permatex ${ }^{\mathrm{TM}}$ self-mixing 5 minute epoxy)

Fig. 2. Components needed to construct the camera housing. Product renderings provided by McMaster-Carr (Cleveland, Ohio, USA). 

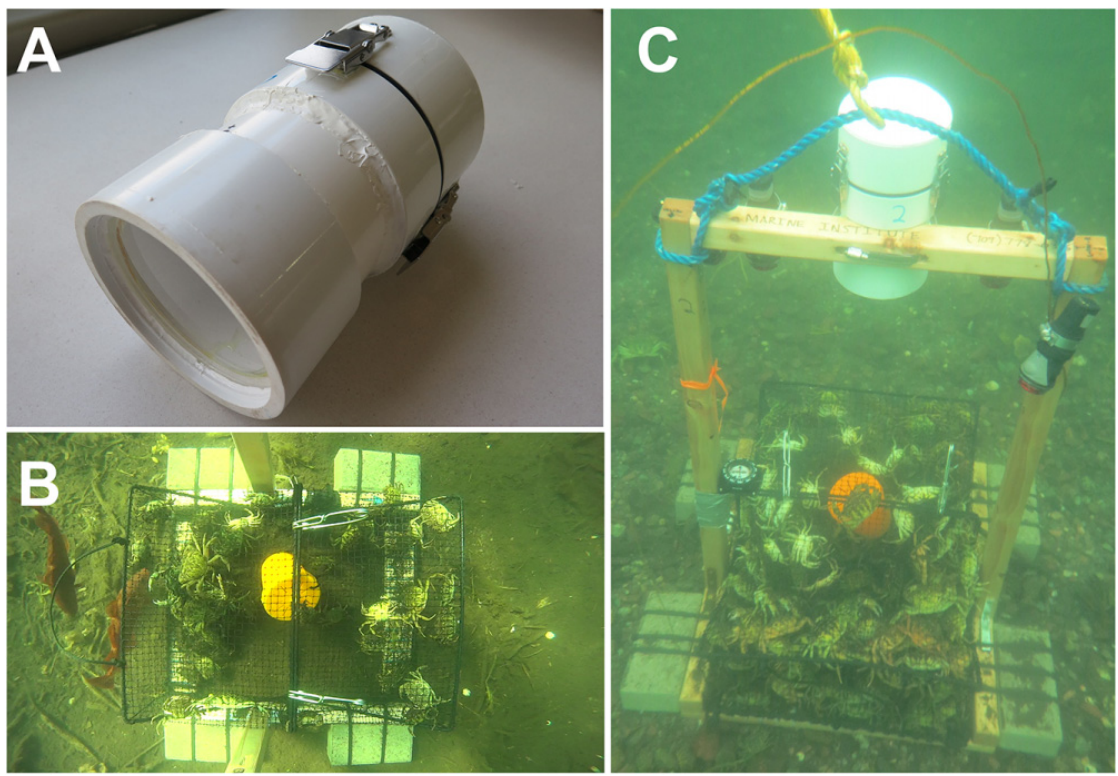

Fig. 3. Photographs depicting (A) a completed camera housing, (B) an example screen grab from a camera system deployment, and (C) the fully assembled camera system, deployed at sea.

full-spectrum lights (Goldsmith and Fernandez 1968; Widder et al. 2005; Weiss et al. 2006). In our specific application, we used Light and Motion (Marina, California, USA) Gobe Plus flashlights equipped with red light attachments (the Gobe Focus Head). We found it preferable to use lights with red LEDs, as opposed to white LEDs covered by a red filter, because the red LED uses less energy to produce the same intensity of light.

The underwater housing requires little maintenance. Although many housings require the use of O-ring grease to facilitate the seal, we do not recommend doing so with our system because we found that it can increase the chance of a leak. If the O-ring is kept clean and free from debris, compressional force alone is enough to maintain a water-tight seal. Be sure to inspect the O-ring regularly for signs of wear and damage. Additionally, if the housing is being used in a salt water environment, it is important to rinse it thoroughly in fresh water after each use.

\section{Hydrostatic pressure testing}

The maximum safe operating depth for these housings depends on the care taken during the construction process. Therefore, we recommend that all housings be tested for leaks either in a hydrostatic chamber if available or in the field at-depth before installing a camera inside. We recommend testing empty camera housings at depths exceeding those intended for use in the study.

To measure the maximum safe operating depth of this housing design, we used a hydrostatic testing chamber. We tested two housings: one that was built to the exact specifications outlined in this note (housing A); and another that was built the same way, but with less sealant around the inside and outside of the viewport (housing B). We tested each housing separately in the hydrostatic chamber by steadily increasing the hydrostatic pressure to the point of failure (i.e., leakage or implosion). We applied water-finding paste around the viewport and O-ring seal on the inside of each camera housing to determine the entry point of leaks. Any contact with water would change the colour of the paste from grey to purple and would indicate the location of a leak. Slow leaks inside the chamber 
were indicated by a gradual drop in pressure inside the chamber, whereas a catastrophic leak (e.g., implosion) would be indicated by an instantaneous drop in pressure.

\section{Results}

We have used these underwater housings to conduct field-based research in coastal waters of Newfoundland, Canada during the summer months of 2015 and 2016 to assess the efficiency of two types of fishing gear designed to catch European green crab (Carcinus maenas) and American lobster (Homarus americanus), respectively. Field research was conducted under Experimental Licenses NL-3133-15 and NL-3271-16 issued by Fisheries and Oceans Canada. The field research only involved invertebrates; therefore, it was classified as a Category A study and was registered with Memorial University's Animal Care Committee. We built a total of seven camera systems that were deployed a total of 160 times, for a combined total of $2794 \mathrm{~h}$ underwater. Cameras were deployed in depths ranging from 2 to $16 \mathrm{~m}$, anywhere from 6 to $26 \mathrm{~h}$ duration. Across the entire study, we experienced an incident where three camera housings experienced minor leaks on the same day in 2015. We identified that the leakage was caused by the use of O-ring grease. Compression forced the greased O-ring out of place, which compromised the seal and caused the leak. As a result, we did not use O-ring grease during any other deployments and experienced no further issues.

\section{Hydrostatic pressure testing results}

Housing A experienced a slow leak at $4760 \mathrm{kPa}$ (equivalent to a depth of $\sim 470 \mathrm{~m}$ ), and housing $\mathrm{B}$ experienced a slow leak at $2000 \mathrm{kPa}$ (equivalent to a depth of $\sim 200 \mathrm{~m}$ ). The water-finding paste indicated that in both camera housings the leaks occurred around the viewport. This large difference demonstrated the importance of taking great care to seal the lens thoroughly. This also suggested that increasing the thickness of the camera housing (e.g., by using schedule 80 PVC) would not necessarily increase the depths at which this design could operate.

\section{Discussion}

Electronics change quickly, but the need to keep them dry does not. It is always necessary to procure an underwater housing to record in situ video, and these housings are often among the most expensive parts of a camera system. It is our observation that although the video quality of offthe-shelf cameras has improved, and cameras have shrunk, they have not improved in their ability to record long-duration videos as battery life and storage capacity are still limiting factors. It is notable that newer action cameras are capable of recording in $4 \mathrm{~K}$ resolution, but these videos are more memory intensive than standard high definition. In addition, aquatic researchers are more limited than their terrestrial counterparts in their ability to rely on motion sensors because of the frequent movement of currents, vegetation, and particulate matter which contribute to falsepositive activations of the camera.

For our system, the total component costs at the time of writing were \$145 USD for each housing, $\$ 320$ USD for the camera, memory card, and battery, and \$40 USD for materials for the wooden frame used to mount the cameras to our particular traps. The lighting solution that we used cost $\$ 650$ USD. The most cost-effective way to produce this housing is to build more than one at a time because many materials (e.g., PVC pipe, O-rings) are sold in pre-set quantities or lengths, so this note will leave the researcher with an excess of materials.

If researchers simply need to record short shallow water videos in well-lit environments, then an action camera with an off-the-shelf housing is sufficient (see Struthers et al. 2015 for review). Timelapse cameras are cheap and widely available, but they do not allow the user to record long, 
continuous videos, which is a necessity for certain applications. In addition, most industrial fishing occurs in water too deep for most consumer camera systems (Morato et al. 2006), so accessing these depths for the length of time needed for fisheries research is more challenging. We see this housing as filling an important niche: an extremely low-cost solution for researchers that need to record long videos at shallow to moderate depths and that do not have access to the necessary funds to purchase specialty equipment. In addition, although construction experience is helpful (especially in the use of a lathe), we believe that a relatively low level of pre-existing technical skill is needed to follow these instructions in comparison with other do-it-yourself camera options currently available (e.g., Cazenave et al. 2014).

There are many uses for camera systems in underwater environments and their flexibility is only limited by the creativity of the researcher. To list a few applications, underwater cameras can be used to study fish behaviour (Hammar et al. 2013; Binder et al. 2014; Domenici et al. 2014), monitor interactions with fishing gear (Jury et al. 2001; Bacheler et al. 2013; Robbins et al. 2013), evaluate bycatch reduction devices (Favaro et al. 2013; Cairns et al. 2014; Lomeli and Wakefield, 2014), assess abundance and community structure (Clarke et al. 2012; Harasti et al. 2014), or map habitat and bathymetry (Schmidt and Rzhanov 2012). However, many studies involving action cameras are still limited by the duration and quality of video they are able to record. We are hopeful that this detailed note will make it easier for researchers to procure and use underwater cameras in their own research to facilitate long-duration video recordings in the underwater environment.

\section{Acknowledgements}

This project was funded by a Marine Environmental Observation Prediction and Response Network (MEOPAR) grant to BF (grant EC1-BF-MUN), as well as by the Canadian Centre for Fisheries Innovation (H-2015-06) and the Government of Newfoundland and Labrador's Department of Fisheries and Aquaculture (NH-77863). NZ and JAB were supported by Ocean Industry Student Research Awards from the Research and Development Corporation of Newfoundland (5404-1914101 and 5404-1915-101, respectively). We thank Cynthia McKenzie, Kiley Best, and Kyle Matheson for support in the field. We also thank the Fish, Food, and Allied Workers Union, ACAP Humber Arm, Fisheries and Oceans Canada, Memorial University's Field Support Services, and the Bonne Bay Marine Station. We thank Terry Bungay and Craig Hollett for contributing to hydrostatic testing of camera housings. Music for supplementary video was provided by www.bensound.com under the creative commons CC BY-ND 3.0 Unported license. Finally, we thank two anonymous reviewers and Paul Winger for their thorough and timely feedback, which greatly improved this manuscript.

\section{Author contributions}

Conceived and designed the study: JAB, NZ, GL, BF. Performed the experiments/collected the data: JAB, NZ, GL, BF. Analyzed and interpreted the data: JAB, NZ, GL, BF. Contributed resources: GL, BF. Drafted or revised the manuscript: JAB, NZ, GL, BF.

\section{Competing interests}

BF is currently serving as a Subject Editor for FACETS, but was not involved in review or editorial decisions regarding this manuscript.

\section{Data accessibility statement}

All relevant data are within the paper, the Supplementary Material, and on Figshare (see Supplementary Material 2). 


\section{Supplementary material}

The following Supplementary Material is available with the article through the journal website at doi:10.1139/facets-2016-0048.

Supplementary Material 1: Detailed list of hardware for housing, product numbers for an online hardware retailer, and price at time of writing.

Supplementary Material 2: https://dx.doi.org/10.6084/m9.figshare.4042932-In this video we demonstrate all steps necessary to construct the underwater camera housing described in the note. Step numbers in the video correspond to each step in the supplementary material. Component labels correspond with labeling in Fig. 2.

Supplementary Material 3: Fully annotated construction guide, including photos demonstrating each step.

\section{References}

Anonymous. 2006. Underwater housing for miniDV. Instructables [online]: Available from: http:// www.instructables.com/id/Underwater-Housing-for-miniDV/.

Bacheler NM, Schobernd ZH, Berrane DJ, Schobernd CM, Mitchell WA, and Geraldi NR. 2013. When a trap is not a trap: converging entry and exit rates and their effect on trap saturation of black sea bass (Centropristis striata). ICES Journal of Marine Science, 70: 873-882. doi:10.1093/icesjms/ fst062.

Binder TR, Thompson HT, Muir AM, Riley SC, Marsden JE, Bronte CR, et al. 2014. New insight into the spawning behavior of lake trout, Salvelinus namaycush, from a recovering population in the Laurentian Great Lakes. Environmental Biology of Fishes, 98: 173-181. doi:10.1007/ s10641-014-0247-6.

Cairns NA, Stoot LJ, Blouin-Demers G, and Cooke SJ. 2014. Refinement of bycatch reduction devices to exclude freshwater turtles from commercial fishing nets. Endangered Species Research, 22: 251-261. doi:10.3354/esr00549.

Cazenave F, Kecy C, Risi M, and Haddock S. 2014. SeeStar: a low-cost, modular and open-source camera system for subsea observations. In Oceans 2014, St. John's, Newfoundland and Labrador, 14-19 September 2014. pp. 1-7. doi:10.1109/OCEANS.2014.7003077.

Clarke C, Lea J, and Ormond R. 2012. Comparative abundance of reef sharks in the Western Indian Ocean. In Proceedings of the 12th International Coral Reef Symposium, Cairns, Australia, 9-13 July 2012.

Domenici P, Wilson ADM, Kurvers RHJM, Marras S, Herbert-Read JE, Steffensen JF, et al. 2014. How sailfish use their bills to capture schooling prey. Proceedings of the Royal Society of London B: Biological Sciences, 281(1784): 20140444. doi:10.1098/rspb.2014.0444.

Favaro B, Duff SD, and Côté IM. 2013. A trap with a twist: evaluating a bycatch reduction device to prevent rockfish capture in crustacean traps. ICES Journal of Marine Science, 70: 114-122. doi:10.1093/icesjms/fss138.

Favaro B, Duff SD, and Côté IM. 2014. Density-dependent catchability of spot prawns (Pandalus platyceros) observed using underwater video. Journal of Ocean Technology, 9: 83-97. 
Favaro B, Lichota C, Côté IM, and Duff SD. 2012. TrapCam: an inexpensive camera system for studying deep-water animals. Methods in Ecology Evolution, 3: 39-46. doi:10.1111/ j.2041-210X.2011.00128.x.

Goldsmith TH, and Fernandez HR. 1968. Comparative studies of crustacean spectral sensitivity. Zeitschrift für vergleichende Physiologie, 60: 156-175. doi:10.1007/BF00878449.

Hammar L, Andersson S, Eggertsen L, Haglund J, Gullström M, Ehnberg J, et al. 2013. Hydrokinetic turbine effects on fish swimming behaviour. PLoS ONE, 8: 1-12. PMID:24358334. doi:10.1371/ journal.pone.0084141.

Harasti D, Gallen C, Malcolm H, Tegart P, and Hughes B. 2014. Where are the little ones: Distribution and abundance of the threatened serranid Epinephelus daemelii (Günther, 1876) in intertidal habitats in New South Wales, Australia. Journal of Applied Ichthyology, 30: 1007-1015. doi:10.1111/jai.12446.

Jury SH, Howell H, O'Grady DF, and Watson WH. 2001. Lobster trap video: in situ video surveillance of the behaviour of Homarus americanus in and around traps. Marine \& Freshwater Research, 52: 1125-1132. doi:10.1071/MF01096.

Lomeli MJM, and Wakefield WW. 2014. Examining the potential use of artificial illumination to enhance chinook salmon escapement out a bycatch reduction device in a Pacific hake midwater trawl. Bycatch Reduction Engineering Program report, 61-66.

Morato T, Watson R, Pitcher TJ, and Pauly D. 2006. Fishing down the deep. Fish and Fisheries, 7 : 24-34. doi:10.1111/j.1467-2979.2006.00205.x.

Nguyen TX, Winger PD, Legge G, Dawe EG, and Mullowney DR. 2014. Underwater observations of the behaviour of snow crab (Chionoecetes opilio) encountering a shrimp trawl off northeast Newfoundland. Fisheries Research, 156: 9-13. doi:10.1016/j.fishres.2014.04.013.

O’Connell AF, Nicols JD, and Karanth KU. 2011. Camera traps in animal ecology: methods and analysis. Springer, New York City, New York. 271 pp.

Renchen GF, Pittman SJ, and Brandt ME. 2012. Investigating the behavioural responses of trapped fishes using underwater video surveillance. Journal of Fish Biology, 81: 1161-1625. PMID:23020564. doi:10.1111/j.1095-8649.2012.03418.x.

Robbins WD, Peddemors VM, Broadhurst MK, and Gray CA. 2013. Hooked on fishing? Recreational angling interactions with the critically endangered grey nurse shark Carcharias taurus in eastern Australia. Endangered Species Research, 21: 161-170. doi:10.3354/esr00520.

Schmidt VE, and Rzhanov Y. 2012. Measurement of micro-bathymetry with a GOPRO underwater stereo camera pair. In Ocean 2012 MTS/IEEE Harnessing Power Ocean, 14-19 October 2012, Virginia, USA. doi:10.1109/OCEANS.2012.6404786.

Sony Corporation. 2014. Digital HD video camera recorder HDR-AS20 handbook. 71 pp. [online]: Available from: http://pdf.crse.com/manuals/4542974111.pdf.

Struthers DP, Danylchuk AJ, Wilson ADM, and Steven JC. 2015. Action cameras: bringing aquatic and fisheries research into view. Fisheries 40, 502-512. doi:10.1080/03632415.2015.1082472. 
Underwood MJ, Winger PD, Fernö A, and Engås A. 2015. Behavior-dependent selectivity of yellowtail flounder (Limanda ferruginea) in the mouth of a commercial bottom trawl. Fishery Bulletin, 113(4): 430-441. doi:10.7755/fb.113.4.6.

Underwood MJ, Winger PD, and Legge G. 2012. Development and evaluation of a new high definition self-contained underwater camera system to observe fish and fishing gears in situ. Journal of Ocean Technology, 7(1): 60-70.

Weiss HM, Lozano-Alvarez E, Briones-Fourzan P, and Negrete-Soto F. 2006. Using red light with fixed-site video cameras to study the behavior of the spiny lobster, Panulirus argus, and associated animals at night and inside their shelters. Marine Technology Society Journal, 40: 86-95. doi:10.4031/002533206787353213.

Widder EA, Robison BH, Reisenbichler KR, and Haddock SHD. 2005. Using red light for in situ observations of deep-sea fishes. Deep Sea Research Part I: Oceanographic Research Papers, 52: 2077-2085. doi:10.1016/j.dsr.2005.06.007. 